Ability of the Confined Explosive

Component Water Gap Test STANAG 4363 to Assess the Shock Sensitivity of MM-Scale Detonators

A. S. Lefrancois, F. Roeske, J. Benterou, C. M. Tarver, R. S. Lee, B. Hannah

February 22, 2006 
This document was prepared as an account of work sponsored by an agency of the United States Government. Neither the United States Government nor the University of California nor any of their employees, makes any warranty, express or implied, or assumes any legal liability or responsibility for the accuracy, completeness, or usefulness of any information, apparatus, product, or process disclosed, or represents that its use would not infringe privately owned rights. Reference herein to any specific commercial product, process, or service by trade name, trademark, manufacturer, or otherwise, does not necessarily constitute or imply its endorsement, recommendation, or favoring by the United States Government or the University of California. The views and opinions of authors expressed herein do not necessarily state or reflect those of the United States Government or the University of California, and shall not be used for advertising or product endorsement purposes.

This work was performed under the auspices of the U.S. Department of Energy by University of California, Lawrence Livermore National Laboratory under Contract W-7405-Eng-48. 


\title{
ABILITY OF THE CONFINED EXPLOSIVE COMPONENT WATER GAP TEST STANAG 4363 TO ASSESS THE SHOCK SENSITIVITY OF MM-SCALE DETONATORS
}

\author{
A.S.Lefrancois(*),F.Roeske, J.Benterrou, C.M.Tarver, R.S.Lee, B.Hanna(**) \\ Energetic Materials Center, Lawrence Livermore National Laboratory, \\ Livermore, CA 94550 - USA
}

(*) Participating guest at LLNL from DGA/Centre d'etudes de Gramat - France

(**) Naval Surface Warfare Center, NSWCDD/G22, 17310 Dahlgren Rd, Dahlgren, VA 22448-5100

The Explosive Component Water Gap Test (ECWGT) has been validated to assess the shock sensitivity of lead and booster components having a diameter larger than $5 \mathrm{~mm}$. Several countries have investigated by experiments and numerical simulations the effect of confinement on the go/no go threshold for Pentaerythritol Tetranitrate (PETN) pellets having a height and diameter of $3 \mathrm{~mm}$, confined by a steel annulus of wall thickness 1-3.5 mm. Confinement of the PETN by a steel annulus of the same height of the pellet with 1-mm wall thickness makes the component more sensitive (larger gap). As the wall thickness is increased to 2-mm, the gap increases a lesser amount, but when the wall thickness is increased to 3.5-mm a decrease in sensitivity is observed (smaller gap). This decrease of the water gap has been reproduced experimentally. Recent numerical simulations using Ignition and Growth model [1] for the PETN Pellet have reproduced the experimental results for the steel confinement up to $2 \mathrm{~mm}$ thick [2] . The presence of a stronger re-shock following the first input shock from the water and focusing on the axis have been identified in the pellet due to the steel confinement. The double shock configuration is well -known to lead in some cases to shock desensitization.

This work presents the numerical simulations using Ignition and Growth model for LX16 (PETN based HE) and LX19 (CL20 based HE) Pellets [3] in order to assess the shock sensitivity of mm-scale detonators. The pellets are $0.6 \mathrm{~mm}$ in diameter and $3 \mathrm{~mm}$ length with different type of steel confinement $2.2 \mathrm{~mm}$ thick and $4.7 \mathrm{~mm}$ thick. The influence of an aluminum confinement is calculated for the standard LX 16 pellet $3 \mathrm{~mm}$ in diameter and $3 \mathrm{~mm}$ in height. The question of reducing the size of the donor charge is also investigated to small scale the test itself. 


\subsection{CONFIGURATIONS AND MODELS}

The reference configuration and the models are presented in the reference [2].

\subsection{SCALE PELLETS}

The diameter and length of the pellets are $0.6 \mathrm{~mm}$ in diameter and $3 \mathrm{~mm}$ long. The annulus steel confinement has the same height and a 2.2 or a $4.7 \mathrm{~mm}$ thick. The mesh resolution is 10 elements/mm, further investigations are needed to increase the mesh resolution.

\subsubsection{Lx16 pellets}

The numerical results of the Go/No Go threshold are presented Table 1 . The water gap is above the Stanag threshold of $29 \mathrm{~mm}$.

Table 1 : Go/No Go thresholds for $0.6 \mathrm{~mm}$ in diameter, $3 \mathrm{~mm}$ long LX16 pellets

\begin{tabular}{|c|c|c|}
\hline Steel confinement thickness & Go, water gap & No Go, water gap \\
\hline $2.2 \mathrm{~mm}$ & $29 \mathrm{~mm}$ & \\
\hline $4.7 \mathrm{~mm}$ & & $35 \mathrm{~mm}$ \\
\hline
\end{tabular}

\subsubsection{Lx19 pellets}

The numerical results of the go/No Go threshold are presented Table 2. The water gap is below the Stanag threshold of $29 \mathrm{~mm}$.

Table 2 : Go/No Go thresholds for $0.6 \mathrm{~mm}$ in diameter, $3 \mathrm{~mm}$ long LX19 pellets

\begin{tabular}{|c|c|c|}
\hline Steel confinement thickness & Go, water gap & No Go, water gap \\
\hline $2.2 \mathrm{~mm}$ & & $29 \mathrm{~mm}$ \\
\hline $4.7 \mathrm{~mm}$ & & $23 \mathrm{~mm}$ \\
\hline
\end{tabular}




\subsection{INFLUENCE OF THE ALUMINUM CONFINEMENT}

The diameter and length of the LX16 pellets are $3 \mathrm{~mm}$ in diameter and $3 \mathrm{~mm}$ long. The steel annulus confinement has the same height and a $1 \mathrm{~mm}, 2 \mathrm{mmor} 3.5 \mathrm{~mm}$ thick.

The numerical results are presented Figure 1. They reproduce with a good accuracy the experiments performed at WIWEB Germany [4].

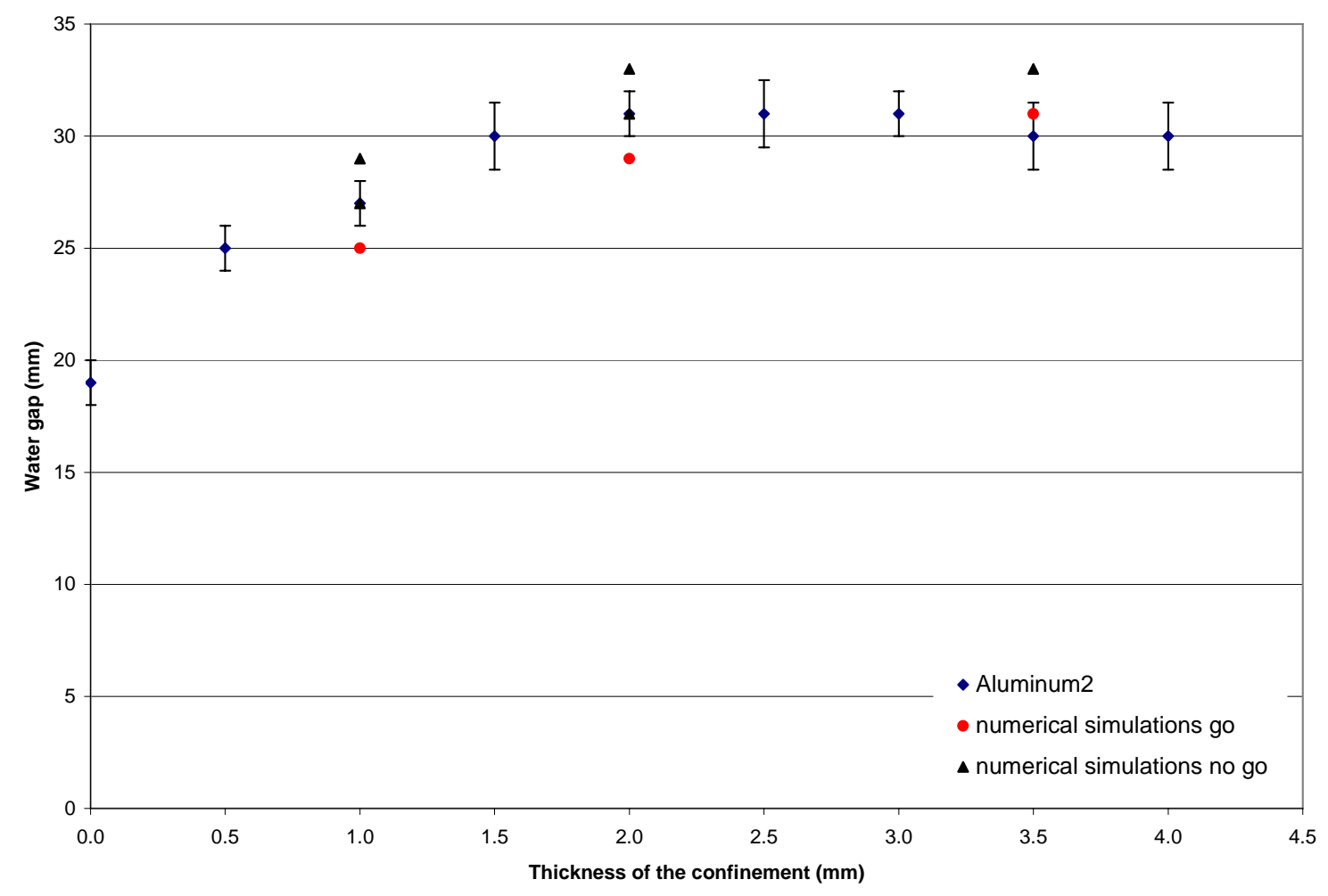

Figure 1 : Go / no go thresholds for different aluminum confinement thickness, PETN based HE $3 \mathrm{~mm}$ in diameter $3 \mathrm{~mm}$ height, comparison between experiments [4] and computations

\subsection{INFLUENCE OF THE LENGTH OF THE PELLET}

The diameter and length of the LX16 pellets are $3 \mathrm{~mm}$ in diameter and $6 \mathrm{~mm}$ long. The annulus steel confinement has the same height and a $1 \mathrm{~mm}, 2 \mathrm{~mm}$ or $3.5 \mathrm{~mm}$ thick.

The experimental results from WIWEB Germany [4] are presented Figure 2. The numerical simulations are presented Table 3 and Figure 3. 
Table 3 : Influence of the height of the HE receptor, PETN based HE $3 \mathrm{~mm}$ in diameter $3 \mathrm{~mm}$ height or $6 \mathrm{~mm}$ height, steel confinement $1 \mathrm{~mm}$ thick

\begin{tabular}{|c|c|c|}
\hline Receptor charge, $\varnothing 3 \mathrm{~mm}$ & Go, water gap & No Go, water gap \\
\hline $6 \mathrm{~mm}$ height & - & $33 \mathrm{~mm}$ \\
\hline $3 \mathrm{~mm}$ height (reference) & $27 \mathrm{~mm}$ & $29 \mathrm{~mm}$ \\
\hline
\end{tabular}

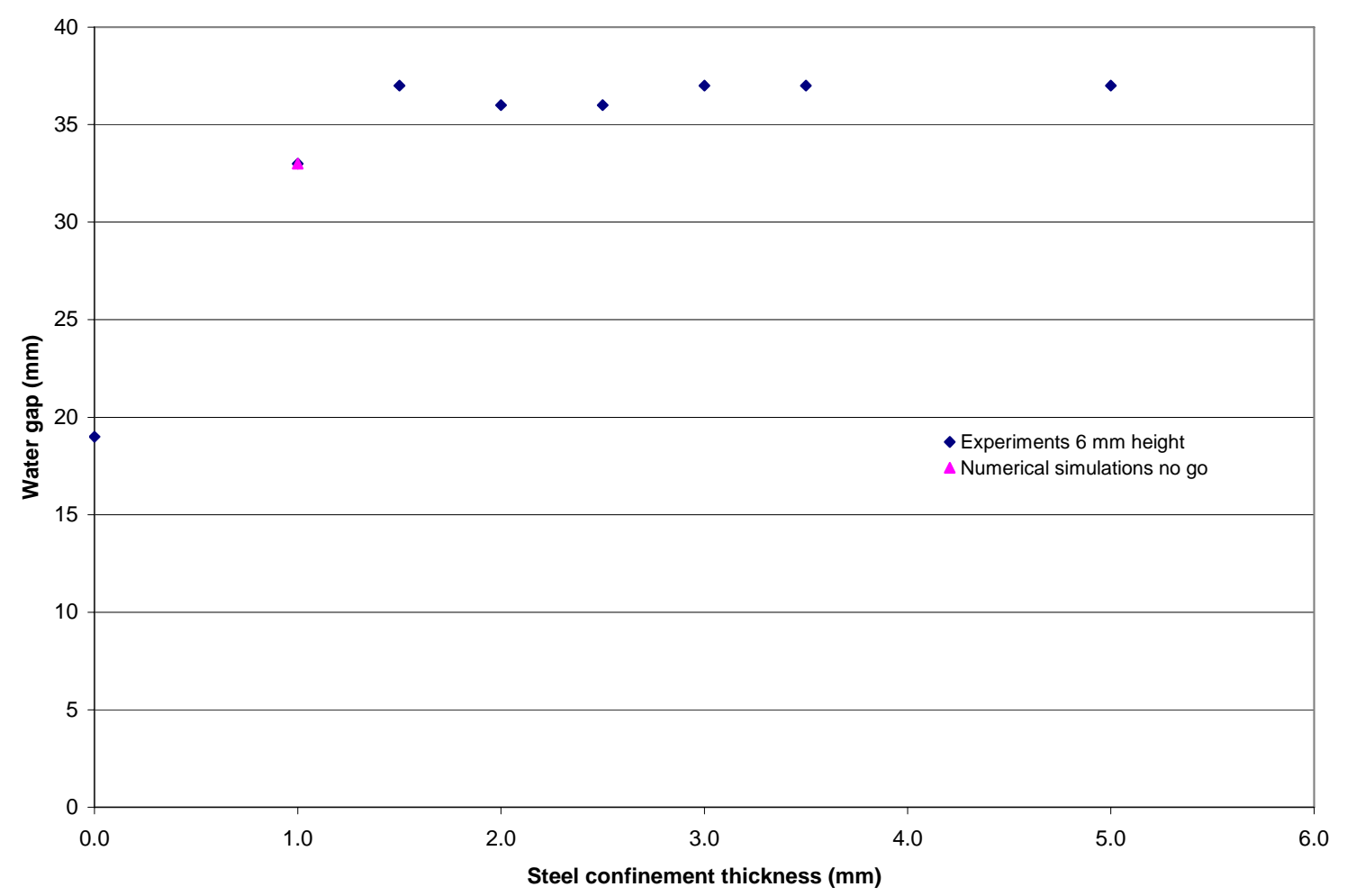

Figure 2 : Go / no go thresholds for different steel confinement thickness, PETN based HE $3 \mathrm{~mm}$ in diameter, $6 \mathrm{~mm}$ height, experiments [4] and calculation 


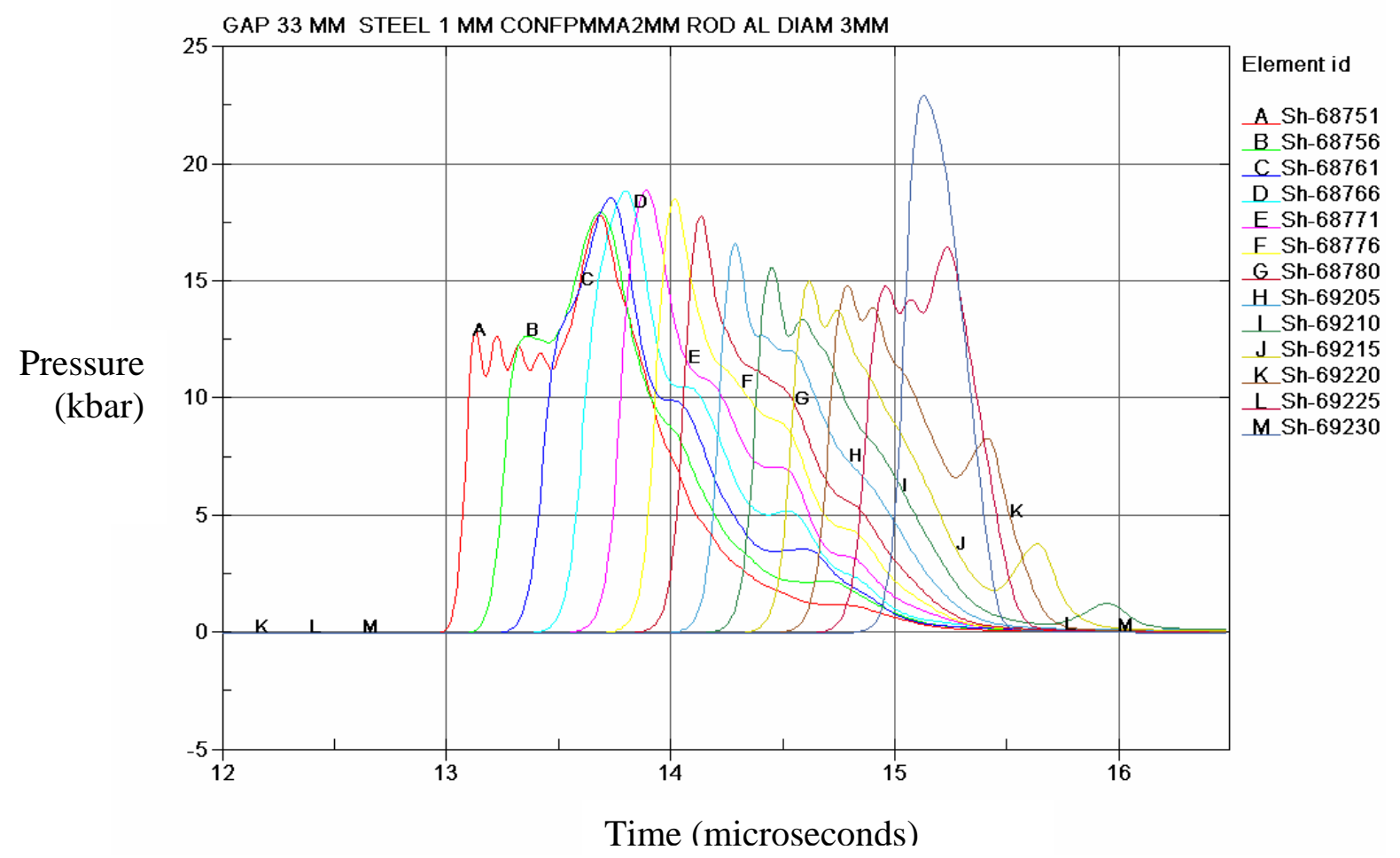

Figure 3 : Lagrangian pressures in $0.5 \mathrm{~mm}$ increments along the axis of the PETN pellet versus time, for $1 \mathrm{~mm}$ thick steel confinement and a water gap of $33 \mathrm{~mm}, 3$ mm in diameter, $6 \mathrm{~mm}$ height $\mathrm{HE}$ pellet

\section{INFLUENCE OF THE DONOR CHARGE}

The stanag 4363 rev.4 final draft allows one of the two following specifications for the donor pellet set-up:

- a plain pellet $\varnothing 21 \mathrm{~mm} \mathrm{~h} 18 \mathrm{~mm}$ initiated at the back,

- $\quad$ or a cavity pellet $\varnothing 21 \mathrm{~mm} \mathrm{~h} 20.3 \mathrm{~mm}$ with a cavity for the detonator.

The chosen reference for the numerical simulation is the plain donor pellet $\varnothing 21$ $\mathrm{mm} \mathrm{h} 18 \mathrm{~mm}$ point initiated at the back, see [2]. A point or a flat initiation of the same donor (diameter $21 \mathrm{~mm}$ and length $18 \mathrm{~mm}$ ) have been calculated and give the same go-no go threshold, Table 4 . The diameter of the flat initiation corresponds to the entire inner diameter of the detonator.

The influence of the cavity pellet filled with the detonator is also investigated. The cavity pellet is modeled as a plain pellet $(\varnothing 21 \mathrm{~mm} \mathrm{~h} 20.3 \mathrm{~mm}$, point initiated at the back) and gives the same go / no - go threshold as the reference. 
The interest is also to small scale the donor charge. Half height of the donor charge was calculated. The numerical results are presented Table 5, Figure 4 and Figure 5. This configuration seems to give the same go / no go threshold than the reference setup. Further investigations are needed to be able to use the half donor instead of the full plain pellet donor. The pressure in water versus the distance is presented Figure 6. The pressure is lower for shorter distances. This could be related with the beta burn model itself, which is chosen to simulate the steady state of detonation and needs time to reach the detonation pressure. After $15 \mathrm{~mm}$ of water, the half donor configuration seems to match the experiment and the numerical set-up with full height of HE donor (point initiated is the standard set-up). The curvature in water needs also to be compared.

Table 4 : Influence of the cavity donor pellet compared to the plain pellet, PETN based HE $3 \mathrm{~mm}$ in diameter, $3 \mathrm{~mm}$ height no confinement

\begin{tabular}{|c|c|c|}
\hline Initiation / Donor charge & Go, water gap & No Go, water gap \\
\hline Point / $\varnothing 21 \mathrm{~mm} \mathrm{~h} 20.3 \mathrm{~mm}$ & - & $16.7 \mathrm{~mm}$ \\
\hline Point / $\varnothing 21 \mathrm{~mm} \mathrm{~h} 20.3 \mathrm{~mm}$ & - & $20.7 \mathrm{~mm}$ \\
\hline Flat / $\varnothing 21 \mathrm{~mm}$ h $18 \mathrm{~mm}$ & $15 \mathrm{~mm}$ & $17 \mathrm{~mm}$ \\
\hline $\begin{array}{c}\text { Point / } \varnothing 21 \mathrm{~mm} \text { h } 18 \mathrm{~mm} \\
\text { (simulation reference) }\end{array}$ & $15 \mathrm{~mm}$ & $17 \mathrm{~mm}$ \\
\hline
\end{tabular}

Table 5 : Influence of the half height donor, PETN based HE $3 \mathrm{~mm}$ in diameter, 3 mm height, steel confinement 1 mm thick

\begin{tabular}{|c|c|c|}
\hline Donor charge & Go, water gap & No Go, water gap \\
\hline Half height donor & $26 \mathrm{~mm}$ & $28 \mathrm{~mm}$ \\
\hline Standard height donor & $27 \mathrm{~mm}$ & $29 \mathrm{~mm}$ \\
\hline
\end{tabular}




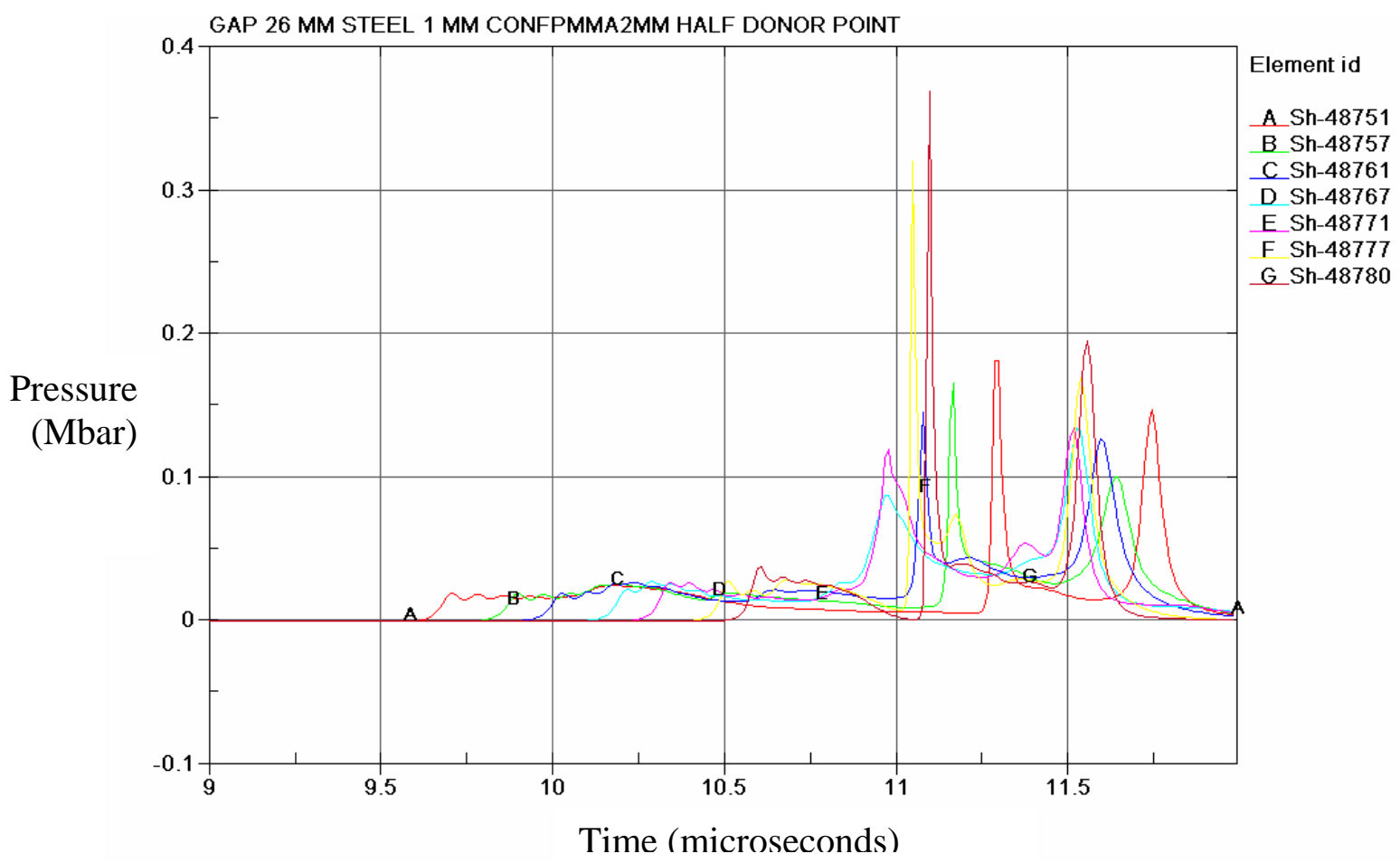

Figure 4 : Lagrangian pressures in $0.5 \mathrm{~mm}$ increments along the axis of the PETN pellet versus time, thick steel confinement and a water gap of $26 \mathrm{~mm}$, Half height donor charge, HE receptor $3 \mathrm{~mm}$ in diameter, $3 \mathrm{~mm}$ height

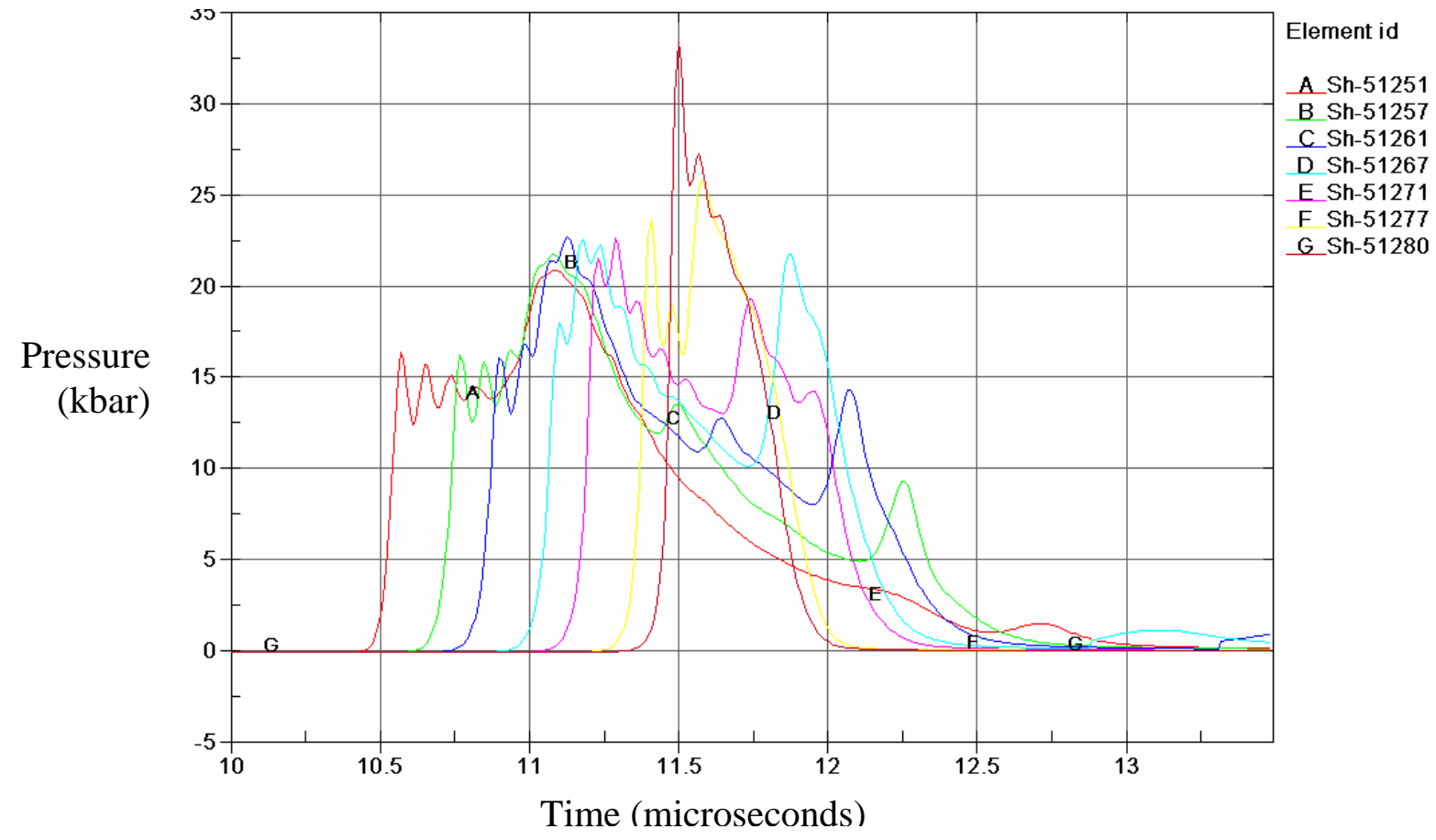

Figure 5 : Lagrangian pressures in $0.5 \mathrm{~mm}$ increments along the axis of the PETN pellet versus time, for $1 \mathrm{~mm}$ thick steel confinement, a water gap of $28 \mathrm{~mm}$, Half height donor charge, HE receptor $3 \mathrm{~mm}$ in diameter, $3 \mathrm{~mm}$ height 


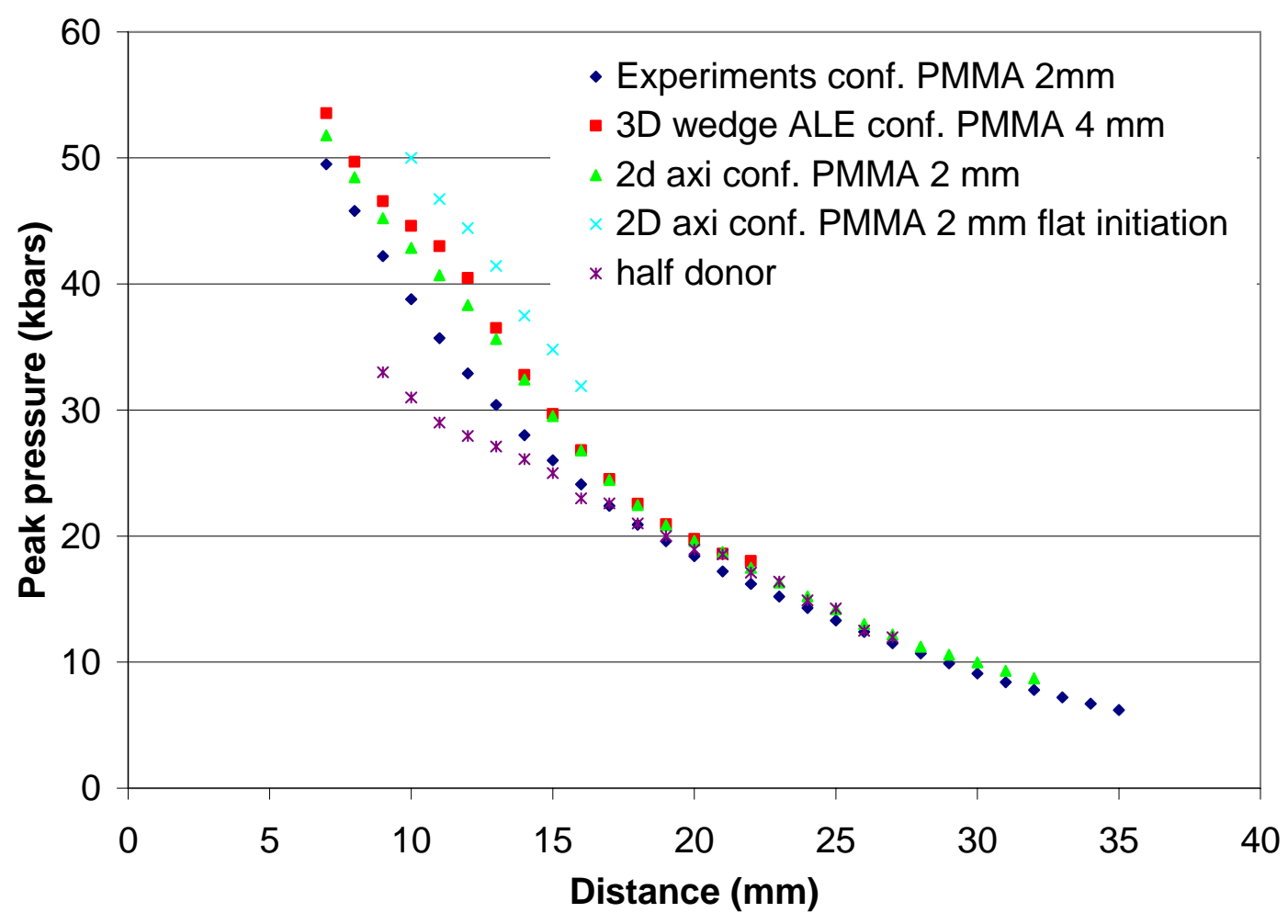

Figure 6 : Peak pressure of the shock front versus tracer distance in water, half donor compared to experiment and the full donor set-ups.

\subsection{REFERENCES}

[1] C.M.Tarver, A.Lefrancois, R.S.Lee, K.Vandersall, Shock Initiationof the PETNbased Explosive LX-16, proposed at the $13^{\text {th }}$ International Detonation Symposium, Norfolk, VA, July 23-28, 2006.

[2] A.S.Lefrancois, R.S.Lee, C.M.Tarver, Possible Shock Desensitization Effect in the Stanag 4363 Confined Explosive Component Water Gap Test (ECWGT) for Components Having a Diameter less than $5 \mathrm{~mm}$, submitted at the 13th International Detonation Symposium 06

[3] C.M.Tarver, R.L.Simpsn, P.A.Urtiew, Sock Initiation of an epsilon-CL20-Estane Formulation, APS 1995

[4] Thomas Eich BWB/WIWEB at the Custodian meeting group Stanag 4383 November 2005, Sevenoaks

* Work performed under the auspices of the U.S. Department of Energy by the Lawrence Livermore National Laboratory under Contract W-7405-Eng-48 